\title{
Quality of Life Measurements in Epilepsy
}

\author{
David Chadwick
}

\begin{abstract}
In the treatment of the patient with epilepsy not only seizure control but quality of life issues are important aspects of management. Aspects that have an impact on the quality of life include seizure frequency and severity, social functioning, psychological well-being, disease specific measures, and general health status.
\end{abstract}

RÉSUMÉ: Évaluation de la qualité de vie dans l'épilepsie. Dans le traitement de l'épilepsie, il est important de contrôler les crises, mais aussi de se préoccuper de la qualité de vie du patient. Plusieurs aspects ont un impact sur la qualité de vie, dont la fréquence et la sévérité des crises, le fonctionnement social, le bien-être psychologique et l'état de santé général.

Can. J. Neurol. Sci. 1996; 23: Suppl. 2-S3-S5

In many branches of medicine and in different health care systems, the development of satisfactory measures of outcome is increasingly emphasised. This is particularly relevant in chronic conditions where a cure is not currently possible but for which medical intervention might have an influence on patients' general well-being and psychosocial adjustment. Historically, clinicians have been distrustful of patient-based assessments of outcomes, considering them to be "soft", subjective, and unreliable. They usually have preferred to use what might be termed "objective" measures of outcome. While the latter are clearly important, there is recognition of the need to include broader-based, patient-assessed outcomes in clinical trials.' It can be argued that improvements in restricted clinical outcomes also should be accompanied by an alteration in the patient's "quality of life".

Clearly, these issues are highly relevant to epilepsy, a disorder complicated by considerable psychosocial disadvantages. Traditional objective measures of outcome have largely concentrated on the assessment of seizure frequency. Thus, in populations of patients with chronic refractory epilepsy, changes in mean seizure frequency are usually the primary outcome variable for clinical trials, while in patients with less severe or newly diagnosed epilepsy, differences between the time to a next seizure or time to a 6 -month, 1- or 2-year remission are often used. ${ }^{2}$

Everyday clinical practice rarely limits itself to such restricted views. Most commonly, the clinician asks the patient "How are you?" For the patient with epilepsy, this immediately invites him to assess the effects of the treatment on seizure control and to balance this against any adverse effects that the patient perceives the treatment might be having. This judgement will inevitably be set within the context of the general and overall psychologic sense of well-being of that individual. Inevitably, the responses to such a simple clinical question are difficult to quantify but are, nevertheless, of considerable clinical relevance.

If satisfactory methodologies for measuring quality of life in epilepsy can be found, this will aid the evaluation of new antiepileptic drugs (AEDs), in attempting to justify relatively expensive interventions (such as the surgical treatment of epilepsy) and even in assessing different systems of healthcare in the disorder.

Intuitively, everyone has an understanding of the concept but will approach quality of life from different perspectives and will use definitions most appropriate to his or her own research. It can, however, be generally agreed that health, at least in people who are ill, is a significant contributor to quality of life. Thus, we might reasonably define health-related quality of life as "representing the functional effect of an illness and its consequent therapy upon the patient as perceived by the patient". ${ }^{3}$

The domains comprising health-related quality of life can also be agreed upon. The first, the physical domain. is concerned with the effects of an illness of a person's ability to carry out normal activities of daily living. Secondly, there is a psychologic and social domain related to the consequences of illness in terms of family and other relationships, employment, and other factors. Many controversies exist, however, about how to measure change within these domains and, indeed, arrive at an overall assessment of quality of life.

Can one easily arrive at a single score that could reflect an individual's quality of life? Simple overall questions are useful,

From the Department of Neurological Sciences. Faculty of Medicine. Walton Centro for Neurology and Neurosurgery. Liverpool. England.

Reprint requests to: David Chadwick, Department of Neurological Science. Faculty of Medicine, Walton Centre for Neurology and Neurosurgery, Rice Lane. Liverpool L9. AE, England 
but when a patient with epilepsy describes themselves as "feeling very well" and having "good quality of life", it is clearly important to know whether this is because they have had no seizures, whether it is because they have recently stopped an antiepileptic drug that gave them unpleasant side-effects, or whether neither of these is the case but they have, within the course of the last week, found a new partner and been offered a job after a long period of unemployment. One can therefore see that any global assessments of quality of life would be greatly complemented by more detailed assessments within the individual domains that contribute to quality of life.

Should the measures that we use to ascertain patients' perceptions about their own quality of life be applied to any chronic illness, or should they be developed specifically for an individual condition? The answer will depend on the questions being asked. If we want to know whether an increase in healthcare resources devoted to the care of epilepsy was more costeffective than a similar increase in the resources available for the care of, for example, diabetes, then quite clearly a generic measure would be necessary. However, if the question is which of two different AEDs is most beneficial in a particular group of patients, then disease-specific measures might be of greater value. Finally, it is essential that any tools used to assess quality of life issues are valid, in that they measure what they set out to measure, are consistent and reliable in the way in which they ascertain information, are sensitive to change and are acceptable to patients.

In recent years there have been a number of initiatives to develop quality of life outcome measures for epilepsy (see Table). Evidence of the reliability and validity of these scales has been established, although information on their sensitivity to change is not always available.

Some of these scales were developed specifically to assess the impact of novel AEDs in clinical trials, and some were developed for other disorders but have been successfully applied to epilepsy. Among those developed recently are the seizure severity scales ${ }^{4.5 .6}$, which attempt to quantify the effects of patient-perceived changes in seizure severity. Most researchers have used a general health measure with the addition of disease-specific measures, while others have developed completely new measures. There are arguments for and against both of these approaches.

Some idea of the usefulness of additional quality of life measures can be illustrated by considering data from a recently published assessment of lamotrigine as add-on therapy for patients with refractory partial epilepsies. ${ }^{7}$ A conventional double-blind, two period, cross-over design was used. Overall, there was a mean $30 \%$ reduction in seizure frequency on lamotrigine compared to placebo. However, the use of lamotrigine was also associated with a number of adverse events and symptoms that were more common during the active drug treatment period. The symptoms included ataxia, diplopia, nausea and vomiting, and rash. It must therefore be questioned whether a perhaps modest reduction in seizure frequency was perceived as beneficial by this patient group in view of the increased incidence of reported adverse events.

A number of measures of psychological well-being were used as well as a novel measure of seizure severity. The latter showed that as well as reducing seizure frequency that lamotrigine had an effect in reducing patient and carer perceived severity of seizures. While there was no difference between scores for
Table. Quality of life measures developed or used in the assessment of antiepileptic drugs.

\begin{tabular}{l}
\hline Physical Measures \\
\hline Seizure diary \\
Liverpool Seizure Severity Scale $^{(4)}$ \\
Chalfont Seizure Severity Scale $(5)$ \\
Veterans Seizure Severity Scale ${ }^{(6)}$ \\
Liverpool Adverse Events Profile (unpublished observations) \\
\hline Social Functioning \\
\hline Social Effects Scale ${ }^{(8)}$ \\
Impact of Epilepsy Scale(9) \\
Life Fulfilment Scale \\
Seals Inventor \\
Stigma Scale \\
\hline Ps)
\end{tabular}

\section{Psychological Well-Being}

Hospital Anxiety and Depression Scale ${ }^{(13)}$

Profile of Mood Scale ${ }^{(14)}$

Affect Balance Scale ${ }^{(15)}$

Mastery Scale ${ }^{(16)}$

Self-Esteem Scale(17.18)

\section{Disease-Specific Measures}

Washington Psychosocial Seizure Inventory ${ }^{(19)}$

MOS SF-55 (20)

Quality of Life Inventory for Epilepsy (QOLIE-89)(21)

The Liverpool Initiative ${ }^{(22)}$

The Queens Square Initiative(23)

General Health Status Measures

Nottingham Health Profile(24)

SF-36(25)

anxiety and depression, patients receiving lamotrigine scored significantly better on an affect-balance scale ${ }^{15}$ and mastery scale $^{16}$ than when taking placebo. While it is impossible to determine whether the apparent improvement in psychological well-being was secondary to the observed changes in seizure frequency and severity or resulted from some independent psychotropic effect of lamotrigine, there seems no doubt that there were overall benefits to treatment with the drug compared to placebo in terms of the patient's general perceptions of their quality of life.

There seems little doubt that quality of life methods will be increasingly used in the assessment of a wide variety of interventions in epilepsy. No single set of measures is currently to be preferred and it is important to use scales that are likely to be sensitive to the questions being asked in any individual study. As well as providing additional information to researchers, quality of life measurements are also important in giving patients a voice in the assessment of treatments in a way that is highly relevant to everyday clinical practice.

\section{REFERENCES}

1. Mattson RH, Cramer JA, Collins JF, et al. Comparison of carbamazepine, phenobarbital, phenytoin and primidone in partial and secondarily generalised tonic-clonic seizures. N Engl J Med 1985; 313: 145-151. 
2. Heller AJ, Chesterman P, Elwes RDC, et al. Phenobarbitone, phenytoin, carbamazepine, or sodium valproate for newly diagnosed adult epilepsy: a randomised comparative monotherapy trial. JNNP 1995; 58: 44-50.

3. Mattson RH, Cramer JA, Collins JF. The Department of Veterans Affairs Epilepsy Comparative Study No. 264 Group. A comparison of valproate with carbamazepine for the treatment of complex partial seizures and secondarily generalised tonic-clonic seizures in adults. N Engl J Med 1992; 327: 765-771.

4. Baker GA, Smith DF, Dewey M, et al. The development of a seizure severity scale as an outcome measure in epilepsy. Epilepsy Research 1991; 8: 245-51.

5. Duncan JS, Sander JWAS. The Chalfont seizure severity scale. J Neurol Neurosurg Psychiatry 1990; 54: 873-6.

6. Cramer JA, Smith DB, Mattson RH, Delgado-Escuata and the VA Epilepsy Cooperative Study $\sim 118$ Group. A method of quantification for the evaluation of antiepileptic drug therapy. Neurology 1983; I Suppl 33: 26-37.

7. Smith D, Baker G, Davies E, et al. Outcomes of add-on treatment with lamotrigine in partial epilepsy. Epilepsia 1993;34:312-322.

8. Chaplin JE, Yepez R, Shorvon S, et al. A quantitative approach to measuring the social effects of epilepsy. Neuroepidemiology 1990; 9: 15I-8.

9. Jacoby A, Baker GA, Smith DF, et al. Measuring the impact of epilepsy: the development of a novel scale. Epilepsy Res 1993; 16: $83-8$.

10. Baker GA, Jacoby A, Smith DF, et al. The development of a novel scale to assess life fulfilment as part of the further refinement of a quality of life model for epilepsy. Epilepsia 1994; 35: 591-6.

11. Brown S, Thomlinson LL. Anticonvulsant side-effects: a self report questionnaire for use in community surveys. Br J Clin Pract, Symp Suppl 1984; 18 : 147-9.

12. Jacoby A. Felt versus enacted stigma: a concept revisited. Evidence from a study of people with epilepsy in remission. Soc Sci Med 1994; 38: 269-74.
13. Zigmond AS, Snaith RP. The hospital anxiety and depression scale. Acta Psychiatr Scand 1983; 67: 361-70.

14. McNair DM, Loor N, Droppleman LF. Manual for the profile of mood states. San Diego, CA: Education and Industrial Testing Services 1981.

15. Bradburn NM. The Structure of Psychological Well-being. Chicago, IL: Aldine 1969.

16. Pearlin LI, Schooler C. The structure of coping. J Health Soc Behav 1978; 19: 2-21.

17. Rosenberg M. Society and the adolescent self-image. Princeton, NJ: Princeton University Press 1965.

18. Demo DH. The measurement of self-esteem: refining our methods. J Pers Soc Psychol 1985; 48: 1490-502.

19. Dodrill CB, Batzel L, Queisser HR, et al. An objective method for the assessment of psychological and social problems among epileptics. Epilepsia 1980; 21: 123-35.

20. Vickrey B, Hays RD, Graber J, et al. A health-related quality of life instrument for patients evaluated for epilepsy surgery. Med Care 1992; 30: 299-319.

21. Devinsky O, Vickrey BG. Quality of life in epilepsy: recent developments in the United States. In: Trimble MR. Dodson WE, eds Epilepsy and Quality of Life. New York, Raven Press 1994: 123-33.

22. Baker GA, Smith DF, Dewey M, et al. The initial development of a health related quality of life model as an outcome measure in epilepsy. Epilepsy Research 1993; 16: 65-81.

23. Kendrik AM, Trimble MR. Repertory grid in the assessment of quality of life in patients with epilepsy: the quality of life assessment schedule. In: Trimble MR, Dodson WE, eds Epilepsy and Quality of Life. New York, Raven Press, 1994: 151-64.

24. Hunt SM, McEwan J, McKenna SP. Measuring health status: a new tool for clinicians and epidemiologists. J R Coll Gen Pract 1985; 35: 185-8.

25. Ware JE, Sherbourne CD. A 36-item short form health survey (SF36). I. Conceptualisation framework and item selection. Med Care 1992; 30: 473-83. 